\title{
Crowding-out in productive and redistributive rent-seeking
}

\author{
Giuseppe Dari-Mattiacci · Eric Langlais • Bruno Lovat • \\ Francesco Parisi
}

Received: 4 June 2006 / Accepted: 30 March 2007 /

Published online: 14 June 2007

(C) Springer Science+Business Media, BV 2007

\begin{abstract}
This paper presents a general rent-seeking model in which participants decide on entry before choosing their levels of efforts. The conventional wisdom in the rent-seeking literature suggests that the rent dissipation increases with the number of potential participants and with their productivity of effort. In this paper, we show that this result of the rent-seeking literature is far from general and applies only when participants are relatively weak and enter the game with certainty. In the presence of strong competitors, the expected total dissipation actually decreases, since participation in the game is less frequent. We further consider the impact of competitors' exit option, distinguishing between "redistributive rent-seeking" and "productive rent-seeking" situations. In redistributive rent-seeking, no social loss results from the fact that all competitors exit the race. In productive rent-seeking, instead, lack of participation creates a social loss (the "lost treasure" effect), since valuable rents are left unexploited. We show that the lost-treasure effect perfectly counterbalances the reduction in rent dissipation due to competitors' exit. Hence, unlike redistributive rentseeking, in productive rent-seeking the total social loss remains equal to the entire rent even when parties grow stronger or the number of players increases.
\end{abstract}

Keywords Rent-seeking $\cdot$ Rent dissipation $\cdot$ Tullock's paradox

G. Dari-Mattiacci $(\bowtie)$

Amsterdam Center for Law and Economics and Tinbergen Institute, University of Amsterdam, Amsterdam, The Netherlands

e-mail: gdarimat@uva.nl

G. Dari-Mattiacci

School of Law, George Mason University, Arlington, VA, USA

E. Langlais

UFR Administration Economique et Sociale, BETA, CNRS et Université Nancy 2, Nancy, France

B. Lovat

Faculté de Droit, Economie et Gestion, BETA, CNRS et Université Nancy 2, Nancy, France

F. Parisi

School of Law, University of Minnesota, Minneapolis, MN, USA 


\section{JEL Classification $\mathrm{C} 72 \cdot \mathrm{D} 72 \cdot \mathrm{K} 00$}

\section{Introduction}

When resources are not-or not yet—subject to clear ownership, private players tend to expend effort in order to gain control over them. Settlers occupy land in newly discovered regions, producers strive for monopoly power, pharmaceutical companies race for the acquisition of patents, and researchers compete for new scientific findings. The rent-seeking literature initiated by Tullock (1967), Krueger (1974) and Posner (1975) and the privateinterest theory of regulation starting with Stigler (1971), Peltzman (1976), Hirshleifer (1976) and Becker (1983) have long analyzed these types of problems, emphasizing the incentives for private parties to invest in rent-seeking activities. ${ }^{1}$ Scholars have occasionally criticized rent-seeking models for bringing about too negative a view of reality. Proponents of alternative views argue that rent-seeking models neglect the fact that rent dissipation is often the by-product of valuable competition in socially beneficial activities, such as scientific or technological research. ${ }^{2}$

In this study, we formulate a general rent-seeking model in order to capture the different welfare effects of redistributive rent-seeking (unproductive competition aimed at the mere reallocation or appropriation of a rent) and productive rent-seeking (where the competitors' expenditures are also instrumental to the discovery or creation of new resources), as distinguished by Demsetz (1976) and Buchanan (1980). ${ }^{3}$ We present a model of redistributive vs. productive rent-seeking with $N$ identical players and study the properties of symmetric equilibria, ${ }^{4}$ challenging a previously uncontested result in the literature, namely, that total rent dissipation increases with the players' productivity of effort and with the number of contestants.

In our model, players first decide whether to enter the game and then, if participating, they choose their effort levels. Players act independently, making both participation and effort choices without observing each other's moves. As in most real-life situations, we postulate that, if a player decides to participate in a rent-seeking contest he needs to undertake a nonnominal initial investment. This assumption brings our analysis in line with the existing literature, where the minimum initial investment is considered as an entry requirement in the competitive race (Yang 1993; Schoonbeek and Kooreman 1997).

In line with the traditional setup, we further assume that in redistributive rent-seeking, the only relevant social cost is given by the parties' dissipation of effort. We identify an interesting relationship between the number of contestants, the parties' strength, and total rent dissipation. When players are relatively weak (i.e., they exhibit low productivity of effort relative to the number of players) the rent dissipation increases with the number of players and with the productivity of effort. In those situations, our results confirm the conventional

\footnotetext{
${ }^{1}$ Recent literature applying the notion of rent-seeking investment focuses on campaign finance (Grossman and Helpman 1996; Coate 2004).

${ }^{2}$ See for example the introduction to Barzel (1997).

${ }^{3}$ The notions of productive rivalry used by Demsetz and of rent-creation employed by Buchanan are analogous to our concept of productive rent-seeking.

${ }^{4}$ Since parties are identical, symmetric equilibria both have a particular intuitive appeal (see Müller 2002, p. 336) and allow for an explicit characterization of the results. Baye et al. (1994) analyze asymmetric equilibria. In their framework, the symmetric equilibrium we find does not arise due to the absence of a minimum participation requirement.
} 
wisdom in the rent seeking literature: total rent dissipation ultimately approaches the entire value of the rent. The subsequent analysis, however, shows that when players are relatively strong, an increase in the number of contestants and/or in their productivity of effort does not increase total rent dissipation. This is because unlike weak contestants who always find it profitable to participate in the game (pure-strategy equilibrium), strong competitors may choose to randomize with respect to their participation in the game (mixed-strategy equilibrium). When there is an increase in the number or in the strength of potential contestants, each of them will rationally choose to play less often.

This brings to light an interesting, and previously unnoticed crowding-out effect. When players have high returns to effort, they will rationally make larger rent-seeking investments. But, surprisingly, the total amount of rent dissipation may actually decrease, because strong players may end up participating less often, in spite of their natural rent-seeking advantage. Similarly, in the presence of a large number of competitors, dissipation may decrease because each player anticipates lower returns from the race and reduces his participation rate. This crowding-out effect dominates the escalation of rent-seeking efforts triggered by higher returns to effort and counteracts the increase in the number of potential participants. Consequently, our results depart substantially from the conventional results in the literature: higher returns to effort do not always lead to an increase in rent dissipation, as generally believed, but may actually lead to a reduction in total rent dissipation.

Moreover, as the number of players increases to very large numbers, the expected number of players who actually enter the game (given by the number of players times the probability of participation) is asymptotically constant. This result also implies that the total rent dissipation decreases to asymptotically approach a constant value.

We extend our analysis to consider the impact of such crowding-out effect in productive rent-seeking situations. Unlike redistributive rent-seeking, lack of participation may lead to a social cost when rent-seeking efforts are conducive to a socially productive outcome. We refer to this additional cost of rent-seeking as the lost treasure effect. This cost occurs when no one engages in the race, leaving valuable rents unexploited. We study how lost treasure costs vary in relation to other rent-seeking costs. We show that crowding-out implies that the lost treasure increases with the number of players and asymptotically approaches a constant value.

Lost treasure effects only appear when strong players are involved and mixed strategies are consequently undertaken. Only in this case, in fact, the probability of participation for each player is lower than 1 , creating the possibility that no one joins the contest. ${ }^{5}$ When players undertake mixed participation strategies, the total social cost of rent-seeking is thus given by the sum of rent dissipation and lost-treasure costs. Interestingly, the sum of rent dissipation and lost treasure costs is shown to be constant and equal to the entire value of the rent, irrespective of the number of players and their productivity of effort. This result brings to mind the claim by early scholars, according to which in equilibrium the entire value of a rent would always be competed away - a claim that was subsequently dismissed (in light of our results, mistakenly) by the prevailing rent-seeking literature. Our framework also enables us to discuss the effects that different categories of rent-seeking activities with varying degrees of productivity have on social welfare. We come to interesting conclusions concerning the desirability of competition among rent-seekers under different circumstances. Our results are easily comparable with the qualitative analysis in Bhagwati (1982).

\footnotetext{
${ }^{5}$ When players are relatively weak, their participation is ensured, such that the only social loss is given by the rent dissipation (which increases in the number of players and in the player's productivity of effort).
} 
In Sect. 2, we put the current study in the context of the existing literature. Section 3 provides the formal analysis; some of the proofs are in the appendix. Section 5 discusses the social cost of several categories of productive and redistributive rent-seeking activities. Section 5 concludes discussing potential extensions of our results and implications of our findings for social and industrial policy.

\section{Rent dissipation and lost treasures in Tullock's paradox}

Tullock's (1967) seminal paper examined how rational individuals expend resources in the pursuit of rents. This contribution provides the basic framework for rent-seeking models, showing how the degree of rent dissipation varies with the value of the prize, the number of contestants and the allocation rules. Parallel analyzes by Becker (1968), Krueger (1974), Posner (1975), Demsetz (1976), Bhagwati (1982), among others, hypothesized a full-dissipation equilibrium, similar to that generated by competitive markets. ${ }^{6}$ In a long-run equilibrium, rents would be competed away by the contestants and rent-seeking investments would thus yield the normal market rate of return.

In his seminal work on "Efficient Rent-seeking", Tullock (1980) developed the insight that the marginal return to rent-seeking expenditures influences the total expenditures on rent-seeking activities. Tullock's (1980) results shook the conventional wisdom in the literature, suggesting that competitive rent-seeking could lead to under- or over-dissipation. Tullock's analysis suggested that, when investments in rent-seeking exhibit increasing returns, aggregate expenditures could exceed the contested prize. This could lead to negative expected returns for the players, making it rational for players to exit the game. But, if no player entered the rent-seeking contest, the prize would remain unclaimed. ${ }^{7}$ Hence, Tullock's well-known paradox. ${ }^{8}$

An important stream of the literature seeks a solution to Tullock's paradox by allowing for randomization of efforts. Baye et al. (1994) introduced a mixed-strategy solution, allowing players to randomize over a finite set of efforts, and studied explicit solutions for some specific cases (with respect to the number of players and the returns on the success function). Our approach is different because it allows players to randomize their participation to the rent-seeking contest before choosing their effort level. In other words, we allow players to choose mixed strategies, randomizing between exerting effort equal to zero (i.e., not entering the game) or entering with a positive effort, which has to be larger than a given fixed entry requirement. This approach captures the reality of many economic activities in which there are entry costs or where participation with a very small investment is not viable.

\footnotetext{
${ }^{6}$ Studying the criminal market, Becker (1968) notes that crime "would not pay", as criminal gains are competed away by (illegal) market forces. Most notably, Posner's (1975) full dissipation hypothesis became popular in the empirical literature and also had a strong appeal in the theoretical one. For a survey of the literature see Buchanan et al. (1980), Congleton and Tollison (1995), Lockard and Tullock (2000), Rowley et al. (1988), and Tollison (2003).

${ }^{7}$ See also Rowley (1991) on the importance of this problem for the development of the idea of rent-seeking.

${ }^{8}$ With rational expectations, parties would realize that the rent-seeking contest would generate negative expected returns, and would consequently choose to exit the contest, if given an opportunity to do so. Tullock (1980) points out the paradoxical result that if no one enters the contest, any one contestant that enters the race would win the prize, regardless of the effort level he chooses. Therefore there is an incentive to enter, destabilizing the hypothesized no-participation equilibrium. Tullock thus concluded that the existence of negative expected returns when all parties participate cannot be used to infer that the equilibrium level of participation will always be zero.
} 
The activities to which our framework applies, as for instance lobbying for a permit or R\&D activities, typically require a minimum level of effort before they can yield any return at all. This framework has also the advantage of being tractable and allows us to characterize the equilibria explicitly.

Hillman and Samet (1987) and Baye et al. (1999) analyze a first-price all-pay auction, a limiting case of Tullock's game. ${ }^{9}$ The latter show that over-dissipation does not result in expectation but may result in particular realizations of the equilibrium. Higgins et al. (1985) and Pérez-Castrillo and Verdier (1992) have sought a solution to Tullock's paradox by transforming the game into a dynamic one and studying the effect of entry on the dissipation of the rent. In this paper, we have a new look at both issues of randomization and entry. We revisit the results reached by two of us (Dari-Mattiacci and Parisi 2005), discussing the problems of participation and optimal effort when there is an entry requirement (minimum participation effort) and when $N$ instead of 2 identical players compete for a rent.

Previous studies have considered the impact of minimum effort requirements in a sequential two-player rent-seeking game (Yang 1993) or in a simultaneous one with constant returns to effort (Schoonbeek and Kooreman 1997), without addressing the lost treasure problem discussed here. A hint to the lost treasure effect can be found in Hillman and Samet (1987, pp. 74-75), where the analysis of the first-price all-pay auction is extended to include a minimum effort requirement. The authors show that there is a positive probability that no party enters the game and discount this probability from the total private value of the contest, without analyzing its implications in terms of social loss.

Appelbaum and Katz (1986) analyze entry when there are fixed entry costs and parties have constant returns to scale (thus, Tullock's paradox does not arise). Gradstein (1995) analyzes a contest with parties of different strength, which results in strong parties crowding out weak parties; in our model, parties are all equal. Amegashie (1999) argues that rent dissipation may decrease in the number of parties but his result derives from the fact that the rent increases in the parties' individual effort, ${ }^{10}$ in our model, the rent is constant. Contrary to previous literature considering randomization strategies, we perform an explicit and extensive comparative statics analysis, not only based on calibrations of the model. Our analysis yields symmetric equilibria and discusses their existence and uniqueness.

\section{Analysis}

\subsection{Model}

We consider $N \geq 2$ identical, risk-neutral individuals who may participate in a contest with a prize equal to $1 .{ }^{11}$ Parties act as to maximize their expected payoffs from the game, conditional on the other players' decisions on entry and effort $X_{i} \in[0,1]$, which they do not observe. The game can be understood as a sequential game with incomplete information: there are $N$ successive rounds; in each round one of the $N$ players chooses his strategy ignoring

\footnotetext{
${ }^{9}$ As the returns to effort in the success function go to infinity, the basic Tullock's game becomes analogous to a first-price all-pay auction.

${ }^{10}$ Clark (2000) argues to the contrary that rent-seeking expenditures should not be counted as rent dissipation when they result in an increase in the value of the rent.

${ }^{11}$ The assumption that the prize is equal to 1 is a choice made for merely methodological convenience and it is equivalent to measuring the parties' investments $X_{i}$ as a fraction of the value of the prize, rather than in absolute terms, as it is more common in the literature. In this way it is easier to evaluate the rent dissipation.
} 
Fig. 1 Party $i^{\prime}$ s strategy set

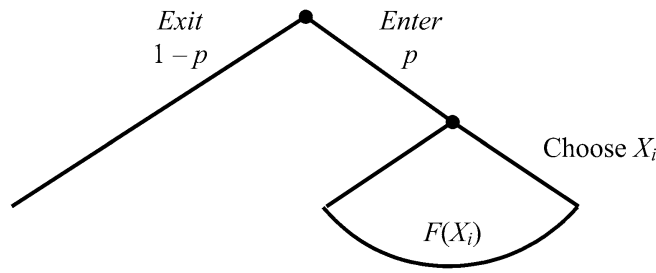

both the number of actual participants to the game and the effort that each of the participants exerts. ${ }^{12}$ In addition, at each round of the game, a given participant $i=1, \ldots, N$ engages in a sequential decision process: in a first stage, he chooses between two actions, namely between entering the game or not entering the game (exit); then, conditionally on his entry, he chooses his effort level $X_{i} \in[0,1]$. Consequently, the strategy space of each player $i$ may be described from the set of possible actions: $\{$ Enter, Exit $\} \cup\left\{\right.$ if Enter, invest $\left.X_{i} \in[0,1]\right\}$.

In order to determine the payoffs, it is necessary to specify the sharing rule for the prize and the way in which each participant anticipates the moves of the others. Let us first focus on the sharing rule. To begin with, $(i)$ if an individual enters the game and exerts effort $X_{i}$, he or she is awarded a share of the prize equal to $X_{i}^{r} /\left(X_{i}^{r}+\sum_{h=0}^{n} X_{h}^{r}\right)$, where $h \neq i$ and $n \leq N-1$ is the number of opponents who have effectively entered the game together with player $i$. Thus, player $i$ 's share in the prize depends on his investment $X_{i}$, the number $n$ of opponents and their efforts $X_{h}$. This fraction can be interpreted either as a real sharing of the prize or as the probability of winning the entire prize. Since players are risk-neutral, both interpretations are formally equivalent. It is easy to see that the exponent $r>0$ (the same for all individuals) represents, as it is usual in the literature, an index of the players' return to effort in the success function, which can be decreasing $(r<1)$, constant $(r=1)$ or increasing $(r>1) .{ }^{13}$ (ii) If player $i$ does not enter the game, he obtains 0 . Finally, (iii) if no player enters the game the prize is not awarded. It follows that the payoff function of player $i$ who has entered the game can be written as:

$$
g_{i}\left(X_{i},\left\{X_{h}\right\}_{h \neq i}\right)= \begin{cases}0 & \text { if } X_{i}=0, \\ \frac{X_{i}^{r}}{X_{i}^{r}+\sum_{h=0}^{n} X_{h}^{r}}-X_{i} & \text { if } X_{i}>0 \text { and } X_{h} \geq 0 \forall h \neq i .\end{cases}
$$

This interpretation allows us to describe the players' behavioral strategies; player $i$ makes the following decisions as illustrated in Fig. 1.

- The player assigns a probability $p_{i}$ to Enter and a probability $1-p_{i}$ to Exit;

- Given entry, the player randomizes on his effort according to the cumulative probability function $F\left(X_{i}\right)$ on $[0,1] .^{14}$

\footnotetext{
${ }^{12}$ This is in contrast to Higgins et al. (1985), in whose two-stage rent-seeking game the individual investment is undertaken knowing exactly the number of participants (a player's decision to participate is obsvervable).

${ }^{13}$ Tullock (1980) first proposed this formulation. See Baye et al. (1994) for an account of the use of Tullok's success function in the literature.

${ }^{14}$ Baye et al. (1994, 1999) shows how randomizing over the set of all possible efforts may solve Tullock's paradox. In our framework, this solution is precluded by the minimum effort requirement, as shown below in the text. They also allow for multiple equilibria. A particular case of the original Tullock game has been extensively tested, namely the limiting case when $r \rightarrow+\infty$ (a first-price all-pay auction). For $N>2$, Baye et al. (1996) show that there exists a continuum of asymmetric equilibria and a unique symmetric one.
} 
Introducing an exogenous minimum effort requirement $X_{0}>0,{ }^{15}$ we can show that the post-entry randomization of effort decisions does not occur in equilibrium, that is, players assign a probability equal to 1 to a certain effort level and 0 to all others. ${ }^{16}$ This leads to a tractable analytical expression for the players' expected payoffs and to several interesting results.

Concerning the way in which players anticipate each others' moves, as usual in a Nashequilibrium analysis, we consider that the strategy choice of each individual is associated with a reasonable belief concerning the other players' strategies. There is an obvious way to formalize these beliefs: since no player can influence the decision of the others but takes them as given, and since the problem is symmetric, it is reasonable for each player to expect all of the others to play the same strategy. That is, we can postulate that all the opponents to player $i$ enter the game with the same probability $p_{h}=q$, and exert the same effort $X_{h}=Y$, for any $h \neq i$. Consequently, we can rewrite player $i$ 's share in the prize simply as $X_{i}^{r} /\left(X_{i}^{r}+n Y^{r}\right)$. Recalling that player $i$ does not observe how many other players enter the game, the number $n$ of opponents he may possibly face is randomly distributed according to a binomial distribution with:

$$
\begin{aligned}
P(n=j) & \equiv \pi_{j} \\
& =\left(\begin{array}{c}
N-1 \\
j
\end{array}\right) q^{j}(1-q)^{N-1-j}=\frac{(N-1) !}{j !(N-1-j) !} q^{j}(1-q)^{N-1-j}
\end{aligned}
$$

corresponding to the probability that the number of opponents playing $(Y, q)$ be equal to $0 \leq j \leq N-1$.

Thus, the expected payoff of a representative player associated to the strategy $(X, p)$ when his opponents play $(Y, q)$ can be now written as follows:

$$
\begin{aligned}
E u\left(g_{i}\left(X_{i}, Y\right)\right) & =U(X, p ; Y, q) \\
& =p \sum_{j=0}^{N-1} \pi_{j}\left(\frac{X^{r}}{X^{r}+j Y^{r}}-X\right)+(1-p) 0 .
\end{aligned}
$$

The individually efficient behavioral strategy is defined as the pair $(X, p)$ that maximizes the expected payoff in (1), under the constraint $p \leq 1 .{ }^{17}$

Using the Lagrangian coefficient $\lambda$ for the constraint, we have the following first order condition on $p$ :

$$
\sum_{j=0}^{N-1} \pi_{j}\left(\frac{X^{r}}{X^{r}+j Y^{r}}\right)-X=\lambda
$$

with $\lambda=0$ if $p<1$ and $\lambda \geq 0$ if $p=1$. Expression (2) yields that when players enter the game with a probability $p<1$, the expected payoff from participating in the game must be

\footnotetext{
${ }^{15}$ Schoonbeek and Kooreman (1997) discuss in details the effect of minimum effort requirements in a different context from ours. The fixed cost of entry is set equal to zero for ease of exposition and without loss of generality.

${ }^{16}$ This result sharply differentiates our analysis from previous randomization solutions to Tullock's paradox.

${ }^{17}$ Introducing the additional constraint $0 \leq p$ is technically possible but $p=0$ cannot be part of a Nash equilibrium; this is the essence of Tullock's paradox. Thus, we explicitly consider only $p>0$.
} 
equal to 0 , as it is the exit payoff. This is a standard condition for mixed strategies, stating that the opponents enter the game with such probability $0<q<1$ and effort $Y>0$ that make player $i$ indifferent between entering and not entering the game $(\lambda=0)$. Otherwise, players participating in the game in a deterministic way $(p=1)$ obtain a non-negative payoff $(\lambda \geq 0)$.

The first order condition on $X$ is:

$$
p\left[\sum_{j=0}^{N-1} \pi_{j}\left(\frac{r X^{r-1} j Y^{r}}{\left(X^{r}+j Y^{r}\right)^{2}}\right)-1\right]=0 .
$$

Expression (3) yields that either the bracketed term $\left[\sum_{j=0}^{N-1} \pi_{j}\left(\frac{r X^{r-1} j Y^{r}}{\left(X^{r}+j Y^{r}\right)^{2}}\right)-1\right]$ is positive and thus $p=0$ (but this cannot be a Nash equilibrium) or:

$$
\sum_{j=0}^{N-1} \pi_{j}\left(\frac{r X^{r-1} j Y^{r}}{\left(X^{r}+j Y^{r}\right)^{2}}\right)=1 .
$$

Expression (4) simply states that the marginal increase in the expected share in the prize must equal the marginal cost of effort. This is also a usual condition, implying that the individually efficient level of effort when participating is such that a player weighs an increase in his expected return to effort against an increase in his cost of effort.

In the following paragraph, we show under what conditions a symmetric Nash equilibrium occurs in pure strategies or in mixed strategies. The reader not interested in the technical details of the analysis may read Proposition 1 and proceed to Sects. $3.3 \mathrm{ff}$., which provide a non technical discussion of our main results.

\subsection{Equilibrium}

We can now define the set of all possible solutions supporting a symmetric Nash equilibrium for this rent-seeking game where players play the strategies described above.

\section{Proposition 1}

(i) Pure-strategy equilibrium: if $r \leq \frac{N}{N-1}$, the unique symmetric Nash equilibrium is such that all $N$ players enter the game with a probability $p^{*}=1$, and exert a positive level of effort equal to $X^{*}=\frac{N-1}{N^{2}} r$.

(ii) Mixed-strategy equilibrium: if $r>\frac{N}{N-1}$, there exists a minimum effort requirement $X_{0}>$ 0 , such that there exists a unique symmetric Nash equilibrium where the $N$ players choose to enter with a positive probability $p^{* *}<1$ and after entry exert a positive level of effort $X^{* *}>X_{0}$. Moreover, $X^{* *}>X^{*}$.

Let us consider these two cases separately.

\subsubsection{Pure-strategy equilibrium}

Consider first the solution with $p=1$, which is associated with a level of $X$ satisfying (4). In a symmetric Nash equilibrium, we must have $X=Y$ and $p=1=q$. Then, (2) gives us the value of $\lambda$, which is the expected payoff in equilibrium, also defined in (1); now, substituting $X=Y$ and $p=1=q$ in (4) and rearranging, we obtain $X^{*}=\frac{N-1}{N^{2}} r$. 
The solution $p^{*}=1$ and $X^{*}=\frac{N-1}{N^{2}} r$ must also verify the complementary slackness condition; thus, substituting in (2), we obtain $\lambda=U\left(\frac{N-1}{N^{2}} r, 1\right)=\frac{1}{N}\left(1-r\left(\frac{N-1}{N}\right)\right) \geq 0$. It is easy to see that this condition is verified only if $r \leq \frac{N}{N-1}$.

Note also that $\left(X^{*}=\frac{N-1}{N^{2}} r, p^{*}=1\right)$ satisfies the second order condition if $r \leq \frac{N}{N-1}$ (see also Baye et al. 1994). It is evident that, given $p^{*}=1, X^{*}=\frac{N-1}{N^{2}} r$ is the unique level of effort satisfying (4).

Remark 1 It is easy to see that $X^{*} \leq \frac{1}{N}$ if $r \leq \frac{N}{N-1}$.

\subsubsection{Mixed-strategy equilibrium}

If $r>\frac{N}{N-1}$, the strategy $\left(X=\frac{N-1}{N^{2}} r, p=1\right)$ cannot support a Nash equilibrium. In fact, in this case we would have $\lambda<0$, implying that players obtain negative expected payoffs. This cannot be an equilibrium because each player could improve his payoff by not entering the game at all and earning 0 . If $r>\frac{N}{N-1}$ is the case, let us consider a solution where $p<1$. Consequently, from (2) we have:

$$
\sum_{j=0}^{N-1} \pi_{j}\left(\frac{X^{r}}{X^{r}+j Y^{r}}\right)=X
$$

which has to be solved together with (4). Once more, in a symmetric Nash equilibrium, we must have $X=Y$ and $p=q<1$. As a result, the system consisting of (4) and (5) can equivalently be written as:

$$
\begin{aligned}
& X=\sum_{j=0}^{N-1} \pi_{j}\left(\frac{1}{1+j}\right), \\
& X=r \sum_{j=0}^{N-1} \pi_{j}\left(\frac{j}{(1+j)^{2}}\right) .
\end{aligned}
$$

Thus, when $r>\frac{N}{N-1}$, a candidate for a symmetric Nash equilibrium is a behavioral strategy corresponding to a pair $\left(p^{* *}, X^{* *}\right)$ which solves $(6-7)$ such that $0<p^{* *}<1$ and $X^{* *} \geq X^{*}$. The latter claim can be formally proven after some tedious manipulations as follows. Note that for any $j$ satisfying $0<j \leq N-1$ the following inequality holds: $\frac{1}{1+j} \geq \frac{1}{N}$; first multiplying by $\pi_{j}>0$ and then summing over $j$, we obtain the following inequalities:

$$
\begin{aligned}
\pi_{j} \frac{1}{1+j} & \geq \frac{1}{N} \pi_{j}, \\
\sum_{j=0}^{N-1} \pi_{j} \frac{1}{1+j} & \geq \frac{1}{N} \sum_{j=0}^{N-1} \pi_{j}=\frac{1}{N} .
\end{aligned}
$$

It is easy to see that the left-hand side is (6), implying that $X^{* *} \geq \frac{1}{N} \geq X^{*}$.

In Appendix 1, it is shown that the system (6-7) has a global maximum corresponding to $\left(p^{* *}, X^{* *}\right)$ only for a minimum value of the effort requirement $X_{0}$. Otherwise, this strategy is not a Nash equilibrium, because an alternative strategy with $\left(p<1, X^{\prime}<X_{0}\right)$ gives the player a positive payoff. To prove that $\left(p^{* *}, X^{* *}\right)$ is a Nash equilibrium, assume that the 
$N-1$ other players choose the behavioral strategy which solves (6-7); and consider an alternative strategy for the $N$ th player where he chooses to set a probability mass $p$ on Enter and a probability mass $1-p$ on Exit and to randomize over all possible levels of efforts on $\left[X_{0}, 1\right]$ with a cumulative probability function $F(Z)$.

The deviation is profitable for him if and only if:

$$
\begin{aligned}
U\left(F(Z), p ; X^{* *}, p^{* *}\right) & =p \int_{X_{0}}^{1}\left(\sum_{j=0}^{N-1} \pi_{j}\left(\frac{Z^{r}}{Z^{r}+j X^{* * r}}-Z\right)\right) d F(Z) \\
& >U\left(X^{* *}, p^{* *} ; X^{* *}, p^{* *}\right)=0 .
\end{aligned}
$$

But this contradicts the definition of $X^{* *}$, since in the post-entry phase we must have $\sum_{j=0}^{N-1} \pi_{j}\left(\frac{Z^{r}}{Z^{r}+j X^{r}}-z\right) \leq U\left(X^{* *}, p^{* *} ; X^{* *}, p^{* *}\right)=0$, for any $Z>X_{0}$ and so $U(F(Z)$, $\left.p ; X^{* *}, p^{* *}\right) \leq 0$. Hence, the $N$ th player has no incentives to deviate.

To prove the uniqueness of the Nash equilibrium where players set a probability mass on Enter, and unitary probability mass on a unique level of effort after entry, it is sufficient to remark that, given $p^{* *}$, the level of $X$ that solves the system (6-7) is by definition the unique level of $X$ that maximizes the post-entry expected payoff of a player.

\subsection{Discussion and comparative statics}

Proposition 1 suggests that the individuals' choice between pure and mixed strategies only depends on the value of the index $r$ relative to the number of players $N$. Defining as the strength factor of a competitor the term $r-\frac{N}{N-1}$, we will call 'strong' players those with a positive strength factor $\left(r>\frac{N}{N-1}\right.$, requiring for example high returns to effort and/or many competitors), and 'weak' players those with a negative (or zero) strength factor ( $r \leq \frac{N}{N-1}$, for example low returns to effort and/or few competitors).

In Proposition 1, it is shown that for weak competitors $\left(r \leq \frac{N}{N-1}\right)$ the natural way to play the game is to adopt pure strategies, that is, it is optimal for all of the players always to enter the game. On the contrary, for strong competitors $\left(r>\frac{N}{N-1}\right)$, it is rational to play mixed strategies and enter the game with a probability lower than 1 . It is easy to see that in this case, we also have $r>\frac{N}{N-1}>1$, that is, strong competitors necessarily have increasing marginal returns to effort. This implies that, as $N$ increases, $\frac{N}{N-1}$ becomes close to 1 , that is, players play mixed strategies even when there are nearly constant marginal returns to effort ( $r$ close to 1), as shown in Fig. 2.

This means that as $N$ increases, players ought to be considered strong competitors at lower levels of $r$. Loosely speaking, Proposition 1 establishes that the rent-seeking contest becomes less appealing for each contestant when there is an increase in the number of potential competitors (which implies a smaller share in the prize) and/or when there is an increase in the players' return to effort (larger equilibrium expenditures). While relatively weak competitors are always ready to enter the contest, stronger contestants prefer to reduce their participation rate. In the next two paragraphs we separately discuss the case of weak competitors and the case of strong competitors and investigate the properties of the equilibrium behavior of the players through a comparative statics analysis. Figure 3 illustrates our results.

\subsubsection{Weak players play pure strategies}

We have seen that when the rent-seeking contest involves weak players $\left(r \leq \frac{N}{N-1}\right)$, it is always optimal for each player to participate in the game, $p^{*}=1$, with a positive effort 
Fig. 2 Parties' strength as a function of $r$ and $N$

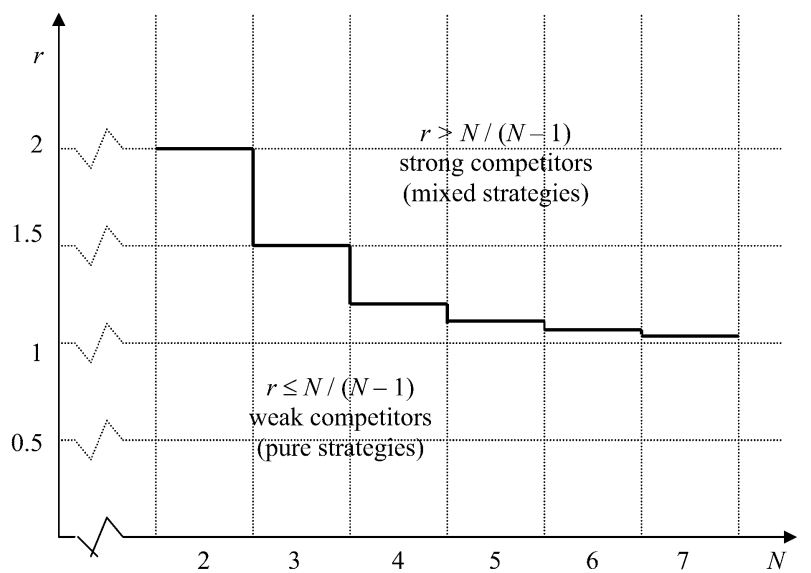

level, $X^{*}=\frac{N-1}{N^{2}} r$. Optimal effort levels increase in the return to effort $r\left(\frac{\partial X^{*}}{\partial r}=\frac{N-1}{N^{2}}>0\right)$, up to the point where the threshold $\hat{r}=\frac{N}{N-1}$ is reached, for which the equilibrium level of effort is $X^{*}=\frac{1}{N}$. Moreover, the individual effort level is decreasing in the number of players $N$ (since $\frac{N-1}{N^{2}}$ is decreasing in $N$ ). In pure strategy, the payoff of each participant is equal to:

$$
U\left(X^{*}, 1 ; X^{*}, 1\right)=\frac{1}{N}\left(1-r\left(\frac{N-1}{N}\right)\right) .
$$

This payoff is non-negative when $r \leq \frac{N}{N-1}$ and it can be easily shown to be decreasing both in $r$ and $N$.

It is interesting to see that, even though players tend to exert more effort when $r$ increases, their payoff actually decreases when their returns to effort increase. An increase in the number of potential competitors $N$ instead has an analogous impact, reducing the parties' efforts as well as their payoffs.

\subsubsection{Strong players play mixed strategies}

When the rent-seeking contest involves strong competitors $\left(r>\frac{N}{N-1}\right)$, the adoption of pure strategies would yield negative payoffs for all players. Tullock's paradox arises precisely from this occurrence.It is thus optimal for players to randomize over entry and participate in the rent-seeking contest with a probability that is positive but lower than 1. Each player enters the game with a probability that makes the other players indifferent between playing and not playing, which implies that the equilibrium expected payoff for each participant is equal to 0 , as it is the payoff obtained when not entering the game.

The study of the comparative statics ${ }^{18}$ shows that, when the marginal return to effort increases, the equilibrium value of the probability of participation in the game decreases $\left(\frac{\partial p^{* *}}{\partial r}<0\right)$, while the equilibrium level of effort increases $\left(\frac{\partial X^{* *}}{\partial r}>0\right)$.

Surprisingly enough, in a Nash equilibrium involving mixed strategies, participants choose a higher effort level than the level chosen in a Nash equilibrium in pure strategies. In a sense, randomization gives incentives to invest more in the game (to make more effort,

${ }^{18}$ The proofs supporting the comparative statics analysis are in Appendix 2. 


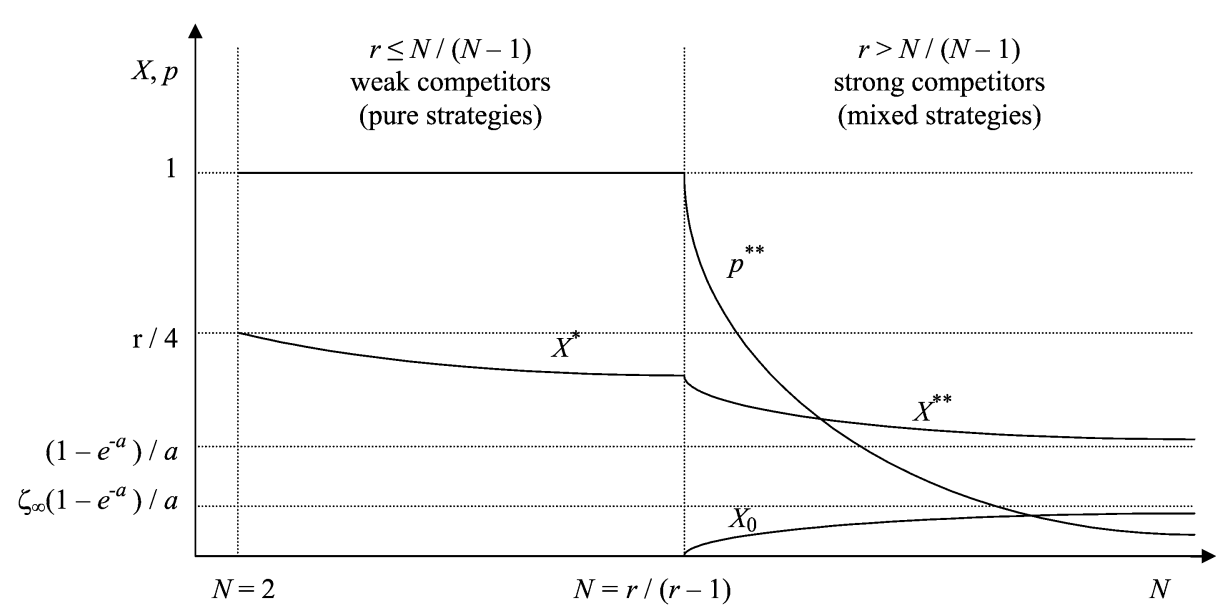

Fig. 3 Rent-seeking expenditure $X$ and probability of participation $p$ as a function of the number of contestants $N$

when choosing to play) than a deterministic behavior. The intuition behind this result can be easily explained as follows. A higher return to effort induces each player to exert a higher level of effort in order to retain a larger share of the prize. However, when all players invest more in the game, their equilibrium shares in the prize remain constant, since the prize is equally shared among them, in spite of their larger expenditures. Thus, all players bear a higher cost of effort which is not compensated by an increase in their shares of the rent and hence results in a decrease in their net payoffs. ${ }^{19}$ As a result, since with a higher productivity of effort players increase their risk of receiving a negative payoff, they will tend to compensate such risk by reducing their probability of participation.

On the contrary, when the number of players increases, both the probability of playing and the optimal effort level for each player tend to decrease. This is due to the fact that the impact of one player's effort is diluted when the number of players increases (larger denominator), and each player may end up sharing the prize with a larger number of parties. An increase in the number of players thus makes the game less attractive for the players exacerbating the risk associated with participation in the contest. To compensate, players reduce both their probability of participation, and their levels of efforts.

Our mixed strategy equilibrium $\left(X^{* *}, p^{* *}\right)$ is sustained by a minimum effort requirement $X_{0}$ which always exists and is uniquely defined for each value of $(r, N)$. Noting that $X_{0}$ and $X^{* *}$ are the only positive roots of (5), we can easily describe how $X_{0}$ and the (positive) difference $X^{* *}-X_{0}$ change when $r$ and $N$ change. In Appendix 2 we prove that, when $r$ goes to infinity, both $X^{* *}$ and $X_{0}$ asymptotically tend to the same value $X_{\infty}=1$ while, when $N$ goes to infinity $X^{* *}$ asymptotically approaches a positive constant, while $X_{0}$ approaches a different positive constant, which is smaller than the former. ${ }^{20}$ Moreover, we show that when

\footnotetext{
${ }^{19}$ Notice that the equilibrium value of the share in the prize is $X^{r} /\left(X^{r}+n X^{r}\right)=1 /(1+n)$ in a round of the game with $n$ actual participants. Hence, in equilibrium, when each participant exerts the same level of effort, the prize is shared equally among them. But, the payoff in the event of $n$ parties entering the game is $1 /(1+n)-X$, and clearly decreases if $X$ increases.

${ }^{20}$ We show that for each possible value of $r>N /(N-1), \lim _{N \rightarrow+\infty} X^{* *}$ exists and is equal to $\left(1-e^{-a}\right) / a$, where $a$ is the unique and non negative solution of the equation: $\Psi(a)=(r-1) / r$ with 
the number of competitors increases, the expected number of participants $N p$ converges to a positive constant $a>0$.

\section{The social cost of productive and redistributive rent-seeking}

In this section, we use the results of the previous analysis to study redistributive and productive rent-seeking. The social costs associated with each of these two forms of rent-seeking are quite different. In a redistributive rent-seeking game, players compete for the reallocation or appropriation of a fixed rent. There is no socially valuable by-product of the rent-seeking contest and the social cost equals $D$, the aggregate value of resources dissipated by the parties in the race.

Unlike redistributive rent-seeking games, productive rent-seeking games are characterized by the fact that the players' expenditures are instrumental to the discovery or creation of new resources. For simplicity, we assume that the social value of the sought-after resource is the same as its private value for the players, which we have normalized to 1 . In these cases, the social cost of rent-seeking should include an additional factor, which should be added to the rent dissipation $D$. When players play mixed strategies, there is a positive probability that no player participates in the game, and that valuable resources will remain unexploited. This lost treasure effect $T$ is to be added to $D$ in the calculus of the social cost, which, in the case of productive rent-seeking games becomes equal to $D+T$.

The actual measure of the social cost in the two cases depends on whether players play pure strategies (the case of relatively weak contestants) or mixed strategies (the case of relatively strong contestants), and thus depends on the return to investment in effort, $r$, and on the number of players, $N$. We shall consider these cases in turn. Figure 4 illustrates our results.

\subsection{The social cost with weak players}

When players are relatively weak $\left(r \leq \frac{N}{N-1}\right)$ expected returns from rent-seeking are positive. Thus, players always take part in the game. The total amount of resources dissipated in a rent-seeking activity is hence equal to the sum of the players' efforts. Since players always participate in the game, resources will never be left unexploited and the social cost of the game in this productive rent-seeking situation would be the same as the social cost of a redistributive rent-seeking game. Therefore, recalling that the individual level of effort is $X^{*}=\frac{N-1}{N^{2}} r$, we can write the social cost rent-seeking as a function of $r$ and $N$, as follows:

$$
D(r, N)=N X^{*}=\frac{N-1}{N} r .
$$

It is easy to see that $D$ is increasing in $r\left(\frac{\partial D}{\partial r}(r, N)=\frac{N-1}{N}>0\right)$, and increasing in $N$ (for $N>2$, the term $\frac{N-1}{N}$ is bounded from above by 1 and increases with $N$ ); moreover, it entails full dissipation for $r=\frac{N}{N-1}$.

It is remarkable that, although the individual levels of efforts drop when the number of players increases, the social cost continues to increase as an effect of more players participating in the game, but it never exceeds the value of the rent.

$\Psi(a)=\int_{0}^{a} \frac{e^{u}-1}{u} d u / \int_{0}^{a} e^{u} d u$. Moreover, $\lim _{N \rightarrow+\infty} X_{0}$ exists and is equal to $\zeta_{\infty}\left(\left(1-e^{-a}\right) / a\right)$ where $\zeta_{\infty}$ is the unique positive solution lower than 1 of the equation:

$$
\zeta^{r-1} g\left(\zeta^{r}\right)=g(1),
$$

where $g(y)=\sum_{j \geq 0}\left(a^{j} / j !\right)(1 /(y+j))$. 


\subsection{The social cost with strong players}

When the rent-seeking contest involves relatively strong players $\left(r>\frac{N}{N-1}\right)$, players risk obtaining negative returns from the game. This risk induces them to undertake mixed strategies, participating in the game with a probability lower than 1 . Since the total number of participants is described by a random variable with a binomial distribution, the ex ante value of the rent dissipation ${ }^{21}$ due to the players' efforts is given by the mean value of the number of participants (which is simply $\sum_{j=1}^{N} j \pi_{j}=N p^{* *}$ ) times the individual level of effort, $X^{* *}$ :

$$
D(r, N)=\sum_{j=1}^{N} j \pi_{j} X^{* *}=N p^{* *} X^{* *} .
$$

In order to analyze the impact of changes in $r$ or $N$, let us rewrite the rent dissipation substituting for $X^{* *}$. Developing and redefining the factorial terms of the binomial law, we obtain:

$$
\begin{aligned}
D(r, N) & =N p^{* *} \sum_{j=0}^{N}\left(\begin{array}{c}
N-1 \\
j
\end{array}\right) p^{* * j}\left(1-p^{* *}\right)^{N-j}\left(\frac{1}{1+j}\right) \\
& =\sum_{j=0}^{N-1} \frac{N(N-1) !}{(j+1) j !(N-(j+1)) !} p^{* * j+1}\left(1-p^{* *}\right)^{N-1-j} \\
& =\sum_{j=1}^{N}\left(\begin{array}{c}
N \\
j
\end{array}\right) p^{* * j}\left(1-p^{* *}\right)^{N-j} \\
& =1-\left(1-p^{* *}\right)^{N} .
\end{aligned}
$$

In redistributive rent-seeking activities, the social cost is equal to the rent dissipation. In productive rent-seeking activities, an additional loss is found since players only play with a probability lower than 1 . It is possible that valuable resources will be left unexploited (lost treasures) when no player enters the game. This "lost treasure" cost can be written as:

$$
T(r, N)=\left(1-p^{* *}\right)^{N} .
$$

Given our normalization of the value of the rent to 1 , the expected dissipation losses are equal to the total probability of participation, while the expected lost treasure losses are equal to the probability that no player enters the game. The sum of the rent dissipation and the lost treasure is always equal to the value of the prize, regardless of actual returns to effort, $r$, or number of players, $N$ :

$$
D(r, N)+T(r, N)=1 .
$$

This result obtains more generally in any mixed strategy equilibrium and follows from the fact that parties must be indifferent between entering and not entering in equilibrium. From this result, it is easy to calculate how rent dissipation and lost treasure vary when the

\footnotetext{
${ }^{21}$ Baye et al. (1999) refer to the ex ante value of the dissipation as 'Expected Aggregate Overdissipation (EAO)'. 


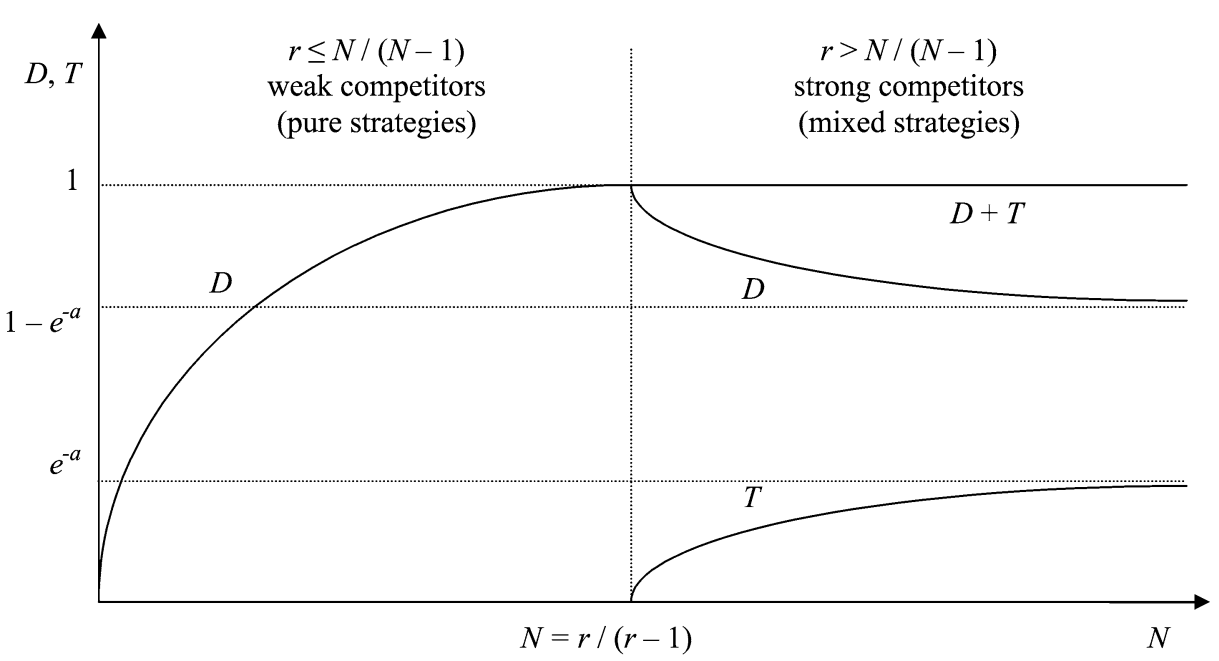

Fig. 4 Rent dissipation $D$ and lost treasure $T$ as a function of the number of contestants $N$

players' return to effort and the number of competitors increase. It is worth noting that the analysis is made simpler by the fact that, in equilibrium, dissipation and lost treasure can be written as functions of the probability with which the players enter the game-disregarding their levels of effort.

With respect to changes in the returns to effort, we have already seen that when mixed strategies are used players with higher returns to effort will tend to play less often. As a result, lost treasure losses will be exacerbated by an increase in the players' returns to effort: $\frac{\partial T}{\partial r}(r, N)>0$. Consequently the value of the dissipation must decrease. Interestingly—and somewhat counterintuitively_-stronger players dissipate fewer resources: $\frac{\partial D}{\partial r}(r, N)<0$.

We can conduct a similar comparative statics analysis with respect to the number of potential contestants. We have previously seen that the probability of actual participation in the rent-seeking contest decreases when the number of players increases, even if there are more players who could eventually participate. Therefore, also in this case, lost treasure losses increase with an increase in $N$. Also in this case we have an interesting result. The total amount of resources dissipated in the rent-seeking race actually decreases with an increase in the number of contestants.

Furthermore, in Appendix 2 we prove that when the number of players goes to infinity, then the rent dissipation asymptotically approaches a constant value given by $D_{\infty}=1-e^{-a}$ and, consequently, the lost treasure tends to $T_{\infty}=e^{-a}$. This result is explained by the fact that although any individual player enters less frequently as the total number of contestants increases, the expected number of effective players remains positive and approaches a constant value. If the expected number of players is constant, then also the lost treasure must be constant; consequently, the total rent dissipation must behave in a similar way in order to ensure that the total social loss remains equal to 1 .

\subsection{The degree of social productivity of rent-seeking activities}

In the previous analysis, we have considered the limiting cases of purely redistributive and productive rent-seeking activities. In purely redistributive rent-seeking games no socially beneficial by-product is generated by the parties' efforts, while in purely productive games 
the parties' efforts are instrumental to the creation or discovery of new resources (what we call the treasure) the social value of which is equal to the parties' private valuation of the rent, which we have assumed to be equal for all parties.

In reality, different activities may exhibit various degrees of social productivity, making the distinction between redistributive and productive rent-seeking rather a matter of degree. Denoting by $W$ the social value of the rent and recalling that its private value for the potential participants is normalized to one in our analysis, it is possible to construct a simple taxonomy of rent-seeking activities, where $W$ measures their degree of social productivity: 22

Destructive rent-seeking $(W<0)$ These are activities that create a benefit for the parties but generate a net social loss for society. This could be the case of lobbying for the creation of a legal monopoly or the introduction of other undesirable restrictions to competition. More obviously destructive rent-seeking activities can be found when criminals compete with one another in the pursuit of an illegal gain. In these cases, even setting aside the effort expenditures brought about by the contest, the parties seek to secure a private gain (in our example, the monopolist's profit or the criminal's gain) that would generate a net social loss (the monopoly deadweight loss or the victim's loss).

Purely redistributive rent-seeking $(W=0)$ These are activities that are of no value for society, such as the lobbying for the assignment of a permit. Parties' compete to secure a private benefit that creates no apparent benefits to society.

Quasi-productive rent-seeking $(0<W<1)$ In quasi-productive rent-seeking activities, the parties compete with one another to appropriate a private benefit, but in the process of doing so they also generate some benefits to society. The social benefit is lower than the value captured by the parties. For example, producers generally invest in advertising to gain a larger share of the market, but their advertising may have some beneficial effect for society at large (e.g., spreading of information about features and quality of a product). In this category of situations, the beneficial social effects (value of advertised information for consumers) might be lower than what is at stake for the parties (the profits from an increased market share).

Productive rent-seeking ( $W=1)$ In this group of cases, the private and social value of the sought-after advantage are the same. Parties compete for the creation or discovery of new resources and fully internalize their value-the private value of such resources is just the same as their value for society. An example is $R \& D$ research where the commercial value of the innovation equals the value to society. This happens when the developer manages to exploit his innovation, capturing the full social value of his discovery.

Super-productive rent-seeking $(W>1)$ In this category of cases, the social benefit exceeds the private benefit that is sought after by the parties. Put differently, the parties cannot capture the full social value of their activity and hence they generate a positive externality to society. An example may be provided by new scientific discoveries that cannot be effectively patented. It is not difficult to imagine that the researcher might not be able to capture the full value of his discovery, with a positive external effect for society.

These distinctions have interesting consequences for the calculus of the social cost of rent-seeking. We have previously discussed the cases of purely redistributive and productive rent-seeking and a few observations should be made at this point with respect to the three additional cases introduced here.

\footnotetext{
${ }^{22}$ If the private value of the rent is indicated by $V$, as in most articles, the degree of social productivity of the activity is $w=W / V$. Our taxonomy can be straightforwardly applied to this formulation.
} 
Let's begin with the case of quasi-productive rent seeking. This case is interesting because, when parties are strong and play mixed strategies, the cost associated with the lost treasure effect is lower than in productive activities, given the fact that the social value of the sought-after rent is less than 1 . As a result, in these cases the total social cost of rentseeking is always less than the private value of the rent and decreases in both $r$ and $N$-the effect of stronger and/or more numerous competition lead to a beneficial decrease in overall dissipation $D$ that dominates the increase in lost treasure effect $T$.

The opposite is true for super-productive rent-seeking activities, in which the increase in lost treasure effect weighs more heavily than the decrease in dissipation. In super-productive rent-seeking activities, the social cost of rent-seeking thus increases in both $r$ and $N$.

Finally, let us consider the case of destructive rent-seeking, where the players' activities generate negative externalities, yielding a negative net value for society. Here, it suffices to notice that whenever the social value of a rent-seeking activity is negative the lost treasure effect comes in the calculus of the social cost with a positive sign. A monopoly that is not granted or a crime that is not committed constitutes a benefit for society. The lack of participation of rent-seekers in the game is beneficial to society. When players undertake mixed participation strategies, the social loss thus equals $D-T$.

This yields to two interesting corollaries. From our results it follows that an increase in the strength of players $r$ reduces the social loss of destructive rent-seeking in two direct ways. An increase in $r$ has two beneficial effects-leading to a decrease in $D$ as well as a decrease in negative $T$ (since $T$ increases). The same holds for an increase in the number of potential participants, $N$, leading to a decrease in both $D$ and negative $T$, and is therefore desirable in the simple setting that we consider.

These findings yield the general conclusion that more competition among potential participants in a contest is welcome for destructive, purely redistributive and quasi-productive activities, has no effect for perfectly productive activities and is detrimental for superproductive activities.

The policy implications are highly relevant and contrary to conventional wisdom. Setting aside other possibly important variables, and focusing on the sum of dissipation and lost treasure costs we are led to the counter-intuitive policy implication that competition is undesirable when the social value of an activity overcomes its private value, and it thus becomes increasingly desirable to restrict competition when the degree of social productivity of the activity increases. Competition is instead desirable in destructive rent-seeking activities and free entry should paradoxically be promoted to reduce the social cost of socially undesirable activities. Our analysis reaches results that are consistent with Bhagwati's (1982) intuition - although, for quite an opposite reason. In Bhagwati (1982), rent-seeking is discouraged because profits are competed away through parties' participation efforts; in our analysis, instead, rent dissipation is limited by lack of participation in the rent-seeking contest. The two analysis converge in the result that competition in rent-seeking erodes profit opportunities for the parties.

\section{Conclusions}

In this paper, we consider an important aspect of Tullock's (1980) rent-seeking paradox, generating results that run contrary to the conventional wisdom in the rent-seeking literature. We show an interesting relationship between number of contestants, returns to rent-seeking investments and total rent dissipation when players have an exit option and are allowed to undertake mixed participation strategies. 
When players are endowed with a weakly productive technology of effort, either with decreasing or constant returns to effort, they always enter the game and never randomize their participation strategy. In contrast, when they have increasing returns to effort, the players' choices depend both on the marginal return to the individual effort and on the number of potential contestants.

The relative strength of the players is measured as a function of these two variables. In both redistributive and productive rent-seeking games, when the players' marginal return to effort is low relative to the number of contestants, they always participate in the contest and the dissipation increases with the number of participants, ultimately approaching the whole value of the rent. When players' marginal return to effort is high relative to their number, players instead tend to invest more in the contest, but tend to participate less often.

As a result, when players are stronger, the dissipation increases steadily up to the point at which total expenditures approach the full rent, rendering it convenient to exit with some positive probability. After this point, in redistributive rent-seeking activities the overall social cost of rent-seeking actually decreases, while in productive rent-seeking activities it remains equal to the full value of the rent. This is because, in productive rent-seeking the reduction in the players expected expenditures is perfectly counterbalanced by the expected value of the rent remaining unexploited when no player takes part in the game.

A similar analysis applies with respect to changes in the number of potential participants. An increase in the number of potential participants reduces the incentive for each player to enter the race. This has different welfare implications in the two cases of redistributive and productive rent-seeking. In the case of redistributive rent-seeking, the total dissipation of socially valuable resources corresponds to the sum of the players' investments in rent-seeking activities. An increase in the number of potential participants, by reducing the incentive for each player to enter the race, may lead to a beneficial reduction in the dissipation of rents.

In the case of productive rent-seeking, the players compete for rents that are associated with socially valuable activities and hence a social loss arises not only from the players' rentseeking expenditures (i.e., the rent-dissipation effect), but also from the lack of exploitation of available rent (i.e., the lost-treasure effect). Here, an increase in the number of potential participants produces two countervailing effects: a reduction in the rent-dissipation effect and an increase in the lost-treasure effect. We show that the rent-dissipation effect is negatively related to the number of contenders, while the lost-treasure effect is positively related to it. Interestingly, the sum of the rent-dissipation effect and the lost-treasure effect does not depend on the number of contenders and equals the full value of the rent.

From a welfare point of view, whether unexploited rents should be computed among the social cost of rent-seeking obviously depends on the nature of the situation. In redistributive rent-seeking situations, if no player participates, no redistribution would take place, but no social cost would result from it. In productive rent-seeking situations, instead, lack of participation would create a social cost (the "lost treasure"), since valuable rents would be left unexploited.

The fact that in $N$-player rent-seeking contests the lost-treasure effect perfectly counterbalances the reduction in rent dissipation due to competitors' exit is, in our view, important to emphasize, as it revives and gives formal support to a lost thread in the rent-seeking literature. By computing how the sum of the players' expenditures and the lost-treasure costs vary with a change in the number of players and returns to effort, we can in fact see that the sum of the expected values of these two costs always amounts to the full value of the rent. This result reconciles the techniques and findings of the most recent rent-seeking literature with the intuitions of the earlier seminal contributions by Becker (1968), Krueger (1974), 
Posner (1975), Demsetz (1976), and Bhagwati (1982), who hypothesized that in equilibrium the entire value of a rent would always be competed away.

These results have relevant policy implications. In redistributive games, an increase in the number of potential contestants reduces each player's incentive to enter the contest and thus decreases the deadweight loss from dissipation. The interesting policy corollary is that by opening up entry in a redistributive game, actual participation may actually be reduced with a resulting reduction in the social loss.

In productive rent-seeking situations, a change in the number of contestants alters the balance between the rent-dissipation and the lost-treasure components of the social cost. An increase in the number of contestants would discourage participation and leave potential value unexploited. Whenever the social value of the treasure is higher than the private value (e.g., the case of a scientific discovery that may have a social value greater than the private benefit captured by the discoverers), the social cost derived from the lost treasure would exceed the social benefit obtainable by a reduction in rent-dissipation. In these situations a reduction in the number of competitors in the research race may lead to greater opportunities for scientific discovery. These results should also be revisited in light of the possibility that the parties can previously invest in improving the effectiveness of their rent-seeking efforts, with a potential increase in overall dissipation. These examples are illustrative of the important implications of our results and of the need to extend the analysis to additional settings with asymmetric rent-seeking players and endogenous rent values, in order to assess their real scope for public policy and institutional design.

Acknowledgements The authors would like to thank Guido Calabresi, Emanuela Carbonara, Gerrit De Geest, Ben Depoorter, Christine Kymn, Bruce Johnsen, Henrik Lando, Alan Lockard, Jacob Nussim, Sander Onderstal, Eric Posner, Roald Ramer, Gordon Tullock, Georg von Wangenheim, Wolfang Weigel, Mark Weinstein, the participants in the 2004 annual conference of the European Association of Law and Economics, the 2006 annual meeting of the American Law and Economics Association, and seminars at George Mason University School of Law and Universiteit van Amsterdam, and two anonymous referees for helpful comments. Earlier versions of this article were circulated as 'Rents, Dissipation and Lost Treasures with $N$ Parties'. G. Dari-Mattiacci gratefully acknowledges the financial support provided by Université Nancy 2.

\section{Appendix 1 Proof of Proposition 1}

Concerning part (i) of the proposition, both the existence and the uniqueness of the results are proven in the paper. Here we provide the complete proof of part (ii) of the proposition. When $r>\frac{N}{N-1}$, the NE strategy $(X, p)$ is defined as the solution to:

$$
\begin{aligned}
X & =\sum_{j=0}^{N-1}\left(\begin{array}{c}
N-1 \\
j
\end{array}\right) p^{j}(1-p)^{N-1-j}\left(\frac{1}{1+j}\right) \\
X & =r\left[\sum_{j=0}^{N-1}\left(\begin{array}{c}
N-1 \\
j
\end{array}\right) p^{j}(1-p)^{N-1-j}\left(\frac{j}{(1+j)^{2}}\right)\right] \\
& =r\left[\sum_{j=0}^{N-1}\left(\begin{array}{c}
N-1 \\
j
\end{array}\right) p^{j}(1-p)^{N-1-j}\left(\frac{1}{1+j}-\frac{1}{(1+j)^{2}}\right)\right]
\end{aligned}
$$

which are the first order conditions (labeled (6-7) in the paper) associated to each player's expected payoff maximization. 
Setting the RHS of (9) equal to the RHS of (10), we obtain: $A=r A-r B$, or equivalently $B=\frac{r-1}{r} A$ with:

$$
\begin{aligned}
A & =\sum_{j=0}^{N-1}\left(\begin{array}{c}
N-1 \\
j
\end{array}\right) p^{j}(1-p)^{N-1-j}\left(\frac{1}{1+j}\right) \\
B & \left.=\sum_{j=0}^{N-1}\left(\begin{array}{c}
N-1 \\
j
\end{array}\right)\right) p^{j}(1-p)^{N-1-j}\left(\frac{1}{(1+j)^{2}}\right) .
\end{aligned}
$$

Thus, more precisely, here we prove the following:

Proposition 2 If $r>\frac{N}{N-1}$, there exists a unique $\left.p \in\right] 0,1\left[\right.$ which solves $B=\frac{r-1}{r} A$.

The proof is subdivided in three steps.

Step 1 In the first stage, we introduce alternative expressions for $A$ and $B$ :

Lemma 1 A can be written as:

$$
A=\frac{1-(1-p)^{N}}{N p}
$$

Proof Remark that since $\left(\begin{array}{c}N-1 \\ j\end{array}\right) p^{j}(1-p)^{N-1-j}\left(\frac{1}{1+j}\right)=\frac{1}{N p}\left(\begin{array}{c}N \\ 1+j\end{array}\right) p^{1+j}(1-p)^{N-(1+j),}$ we have:

$$
A=\frac{1}{N p} \sum_{j=1}^{N}\left(\begin{array}{c}
N \\
j
\end{array}\right) p^{j}(1-p)^{N-j}
$$

and straightforward manipulations yield (11).

Lemma 2 B can be written as:

$$
B=-\frac{(1-p)^{N}}{N p}\left[\sum_{j=0}^{N-1} \frac{1}{1+j}\left(1-\frac{1}{(1-p)^{1+j}}\right)\right]
$$

Proof To see this, let us develop the polynomial $(p x+(1-p))^{N-1}$, to obtain:

$$
(p x+(1-p))^{N-1} \equiv \sum_{j=0}^{N-1}\left(\begin{array}{c}
N-1 \\
j
\end{array}\right) p^{j} x^{j}(1-p)^{N-1-j}
$$

Thus, integrating over $x$ from 0 to $t$, we have:

$$
\int_{0}^{t}(p x+(1-p))^{N-1} d x=\int_{0}^{t}\left(\sum_{j=0}^{N-1}\left(\begin{array}{c}
N-1 \\
j
\end{array}\right) p^{j} x^{j-1}(1-p)^{N-1-j}\right) d x
$$


The RHS of (14) is:

$$
\begin{gathered}
\left(\sum_{j=0}^{N-1}\left(\begin{array}{c}
N-1 \\
j
\end{array}\right) p^{j}(1-p)^{N-1-j}\right)\left(\int_{0}^{t} x^{j} d x\right) \\
=\sum_{j=0}^{N-1}\left(\begin{array}{c}
N-1 \\
j
\end{array}\right) p^{j}(1-p)^{N-1-j}\left(\frac{t^{1+j}}{1+j}\right)
\end{gathered}
$$

while the LHS is:

$$
\frac{1}{N}\left[\frac{(p x+(1-p))^{N}}{p}\right]_{0}^{t}=\frac{1}{N} \frac{(p t+(1-p))^{N}-(1-p)^{N}}{p} .
$$

As a result, (14) can be written as:

$$
\frac{1}{N} \frac{(p t+(1-p))^{N}-(1-p)^{N}}{p t}=\sum_{j=0}^{N-1}\left(\begin{array}{c}
N-1 \\
j
\end{array}\right) p^{j}(1-p)^{N-1-j}\left(\frac{t^{j}}{1+j}\right)
$$

Now, the LHS of (15) can be written as:

$$
\frac{1}{N} \frac{(p t+(1-p))^{N}-(1-p)^{N}}{p t}=\frac{1}{N} \sum_{j=0}^{N-1}(p t+(1-p))^{j}(1-p)^{N-1-j}
$$

To see this, let us define the sum:

$$
S=\sum_{j=0}^{N-1}(p t+(1-p))^{j}(1-p)^{N-1-j} .
$$

Multiplying $S$ by $(1-p)$ yields:

$$
(1-p) S=(1-p)^{N}+(p t+(1-p)) S-(p t+(1-p))^{N} .
$$

Thus:

$$
(p t+(1-p)) S-(1-p) S=(p t+(1-p))^{N}-(1-p)^{N}
$$

and solving for $S$ yields the result.

Let us now integrate the RHS of (15) over $t$ from 0 to 1 ; this yields:

$$
\begin{gathered}
\int_{0}^{1}\left(\sum_{j=0}^{N-1}\left(\begin{array}{c}
N-1 \\
j
\end{array}\right) p^{j}(1-p)^{N-1-j}\left(\frac{t^{j}}{1+j}\right)\right) d t \\
=\sum_{j=0}^{N-1}\left(\begin{array}{c}
N-1 \\
j
\end{array}\right) p^{j}(1-p)^{N-1-j}\left(\int_{0}^{1} \frac{t^{j}}{1+j} d t\right) \\
=\sum_{j=0}^{N-1}\left(\begin{array}{c}
N-1 \\
j
\end{array}\right) p^{j}(1-p)^{N-1-j}\left(\frac{1}{(1+j)^{2}}\right)
\end{gathered}
$$


Integrating now the LHS of (15) over $t$ from 0 to 1 , we have:

$$
\begin{aligned}
& \frac{1}{N} \int_{0}^{1}\left(\sum_{j=0}^{N-1}(p t+(1-p))^{j}(1-p)^{N-1-j}\right) d t \\
& \quad=\sum_{j=0}^{N-1}(1-p)^{N-1-j}\left(\int_{0}^{1}(p t+(1-p))^{j} d t\right) \\
& =\frac{1}{N}\left[\sum_{j=0}^{N-1}(1-p)^{N-1-j} \frac{1}{1+j}\left(\frac{1-(1-p)^{1+j}}{(1-p)^{1+j}}\right)\right] \\
& =-\frac{(1-p)^{N}}{N p}\left[\sum_{j=0}^{N-1} \frac{1}{1+j}\left(1-\frac{1}{(1-p)^{1+j}}\right)\right]
\end{aligned}
$$

Hence, setting (16) equal to (17), gives us the result in (12).

Step 2 In the second step, we change the unknown variable. Before that, note that the equation to be solved $B=\frac{r-1}{r} A$, using Lemma 1 and 2 is now:

$$
-\frac{(1-p)^{N}}{N p}\left[\sum_{j=0}^{N-1} \frac{1}{1+j}\left(1-\frac{1}{(1-p)^{1+j}}\right)\right]=\left(\frac{r-1}{r}\right)\left(\frac{1-(1-p)^{N}}{N p}\right)
$$

or:

$$
\sum_{j=0}^{N-1} \frac{1}{1+j}\left(1-\frac{1}{(1-p)^{1+j}}\right)=\left(\frac{r-1}{r}\right)\left(\frac{(1-p)^{N}-1}{(1-p)^{N}}\right)
$$

or:

$$
\sum_{j=0}^{N-1} \frac{1}{1+j}-\sum_{j=0}^{N-1} \frac{1}{1+j} \frac{1}{(1-p)^{1+j}}=\frac{r-1}{r}\left(1-\frac{1}{(1-p)^{N}}\right) .
$$

Finally, let us define $x=\frac{1}{1-p}$, such that $x>1$ as long as $\left.p \in\right] 0,1[$; thus, (18) can be written as:

$$
\sum_{j=0}^{N-1} \frac{1}{1+j}-\sum_{j=0}^{N-1} \frac{1}{1+j} x^{1+j}=\frac{r-1}{r}\left(1-x^{N}\right) .
$$

\section{Lemma 3}

$$
\sum_{j=0}^{N-1} \frac{1}{1+j} x^{1+j}=\int_{0}^{x}\left(\frac{1-t^{N}}{1-t}\right) d t
$$

Proof It is well known that:

$$
\sum_{j=0}^{N-1} t^{j}=\frac{1-t^{N}}{1-t}
$$


Thus, integrating over $t$ from 0 to $x$ leads to:

$$
\int_{0}^{x}\left(\frac{1-t^{N}}{1-t}\right) d t=\int_{0}^{x} \sum_{j=0}^{N-1} t^{j} d t=\sum_{j=0}^{N-1} \int_{0}^{x} t^{j} d t=\sum_{j=0}^{N-1} \frac{1}{1+j} x^{1+j}
$$

which is the result.

Step 3 In the third step, we solve (19) for the new variable $x$. Equation (19) can be framed as the implicit function $F(x)=0$, where:

$$
F(x)=\frac{r-1}{r}\left(1-x^{N}\right)+\int_{0}^{x}\left(\frac{1-t^{N}}{1-t}\right) d t-\sum_{j=0}^{N-1} \frac{1}{1+j}
$$

whose first derivative (for $x>1$ ) is:

$$
F^{\prime}(x)=\frac{x^{N-1}[N(r-1)-(N(r-1)-r) x]-r}{r(x-1)} .
$$

The function $F$ reaches an extremum for the set of values of $x(>1)$ corresponding to: $F^{\prime}(x)=0$. These are the values that solve:

$$
N(r-1)-(N(r-1)-r) x=r x^{1-N} .
$$

Remark that, on the one hand, the LHS corresponds to a linear function $f(x)=N(r-$ 1) $-(N(r-1)-r) x$ which is increasing when $N(r-1)-r<0$ (or equivalently $r<\frac{N}{N-1}$ ) but decreasing when $N(r-1)-r>0$ (or equivalently $r>\frac{N}{N-1}$ ). On the other hand, the RHS of (20) is a quasi-hyperbola $g(x)=r x^{1-N}$ which is decreasing and convex. If $r \leq \frac{N}{N-1}$ these two curves intersect once (for $x=1$ ) and if $r>\frac{N}{N-1}$ they intersect twice. Thus, we have a single relevant case, ${ }^{23}$ that is $N(r-1)-r>0$ (or equivalently $r>\frac{N}{N-1}$ ).

We can prove:

Lemma 4 Assume $r>\frac{N}{N-1} ; f(x)$ and $g(x)$ intersect twice: once for $x=1$, and once for $x>1$.

Proof When $r>\frac{N}{N-1}, f(x)$ is monotone decreasing, with $f(0)=N(r-1)>0$. In addition, $g(x)=r x^{1-N} \rightarrow+\infty$ when $x \rightarrow 0$. For $x=1$, it is easy to see that $f(1)=g(1)=r$, moreover, for $x=1, g(x)$ has a steeper slope than $f(x)$ (since $-N(r-1)+r>r(1-N)$ ) thus both curves intersect twice and the first time for $x=1$.

Lemma 5 Assume $r>\frac{N}{N-1}$; there exists a unique $x>1$ which solves $F(x)=0$.

Proof Recall that according to Lemma $3 \lim _{x \rightarrow 1}[F(x)]=0$. When going to infinity, any polynomial behaves as its terms with the higher exponent. As a result, when $x \rightarrow+\infty, F(x)$ looks like $\left[\frac{1}{N}-\frac{r-1}{r}\right] x^{N}$; thus, $F(x) \rightarrow-\infty$ as $x \rightarrow+\infty$, given that $\frac{1}{N}-\frac{r-1}{r}=\frac{r+N-r N}{r N}<0$

\footnotetext{
${ }^{23}$ Recall that, as shown in Proposition 1, when $N(r-1)-r<0$ (or equivalently $r<N /(N-1)$ ), there only exists one Nash equilibrium in pure strategies.
} 
by assumption. Now, according to Lemma 4, the sign of $F^{\prime}$ alternates on ]1, $\infty$ [, being first positive and then negative. This completes the proof that there exists a unique $x>1$ (hence a unique $p \in] 0,1[$ ) which solves $F(x)=0$.

We have found a unique $(X, p)=\left(X^{* *}, p^{* *}\right)$ solving the first order conditions (9-10).

Finally, steps 1 to 3 together prove Proposition 2 if we can show that for a convenient value of $X_{0}$, for $r>\frac{N}{N-1}$ and for any individual who wants to enter the game, the strategy $\left(X^{* *}, p^{* *}\right)$ is indeed optimal. In other words, we need to study the function:

$$
K(X)=\sum_{j=0}^{N-1} \pi_{j}\left(\frac{X^{r}}{X^{r}+j X^{* * r}}-X\right)
$$

Let us consider:

$$
F(\zeta)=\sum_{j=0}^{N-1} \pi_{j} \frac{\zeta^{r}}{\zeta^{r}+j} \quad \text { and } \quad X^{* *}=F(1)=\sum_{j=0}^{N-1} \frac{\pi_{j}}{1+j}
$$

where $\pi_{j}=\left(\begin{array}{c}N-1 \\ j\end{array}\right) p^{* * j}\left(1-p^{* *}\right)^{N-1-j}$ and $r$ is a given number greater than $\frac{N}{N-1}$.

Writing $X=\zeta X^{* *}$, the equality $K(X)=0 \Leftrightarrow \sum_{j=0}^{N-1} \pi_{j}\left(\frac{X^{r}}{X^{r}+j X^{* * r}}\right)=X$ becomes:

$$
F(\zeta)=\sum_{j=0}^{N-1} \pi_{j} \frac{\zeta^{r}+j-j}{\zeta^{r}+j}=\sum_{j=0}^{N-1} \pi_{j}\left(1-\frac{j}{\zeta^{r}+j}\right)=\zeta X^{* *}
$$

and then:

$$
1-\sum_{j=1}^{N-1}\left(\frac{j \pi_{j}}{\zeta^{r}+j}\right)=\zeta X^{* *} \Leftrightarrow 1-\zeta X^{* *}=\sum_{j=1}^{N-1}\left(\frac{j \pi_{j}}{\zeta^{r}+j}\right) .
$$

We can see that the LHS of this equation corresponds to a linear decreasing function $H(\zeta)=1-\zeta X^{* *}$ and the RHS corresponds to a sum of decreasing classical functions $\frac{j \pi_{j}}{\zeta^{r}+j}$.

For every $\zeta \in\left[0,+\infty\left[, G(\zeta)=\sum_{j=1}^{N-1}\left(\frac{j \pi_{j}}{\zeta^{r}+j}\right)\right.\right.$ is differentiable at $\zeta$ and the inequality

$$
G^{\prime}(\zeta)=\sum_{j=1}^{N-1}-j \frac{\pi_{j}}{\left(\zeta^{r}+j\right)^{2}} \zeta^{r-1} r \leq 0
$$

shows that $G$ is a decreasing function from $\left[0,+\infty\left[\right.\right.$ to $\left[1-\pi_{0}, 0[\right.$ :

$$
\forall \zeta \geq 0, \quad 0 \leq G(\zeta) \leq 1-\pi_{0}
$$

It is easy to see that:

$$
\begin{aligned}
H(1) & =1-X^{*} \\
& =1-\sum_{j=0}^{N-1}\left(\frac{\pi_{j}}{1+j}\right)=\sum_{j=0}^{N-1} \pi_{j}-\sum_{j=0}^{N-1}\left(\frac{\pi_{j}}{1+j}\right)=\sum_{j=1}^{N-1}\left(\frac{j \pi_{j}}{1+j}\right)=G(1) .
\end{aligned}
$$


Moreover, according to the definition of $p^{* *}, G(\zeta)$ has for $\zeta=1$ the same slope as $H(\zeta)$ :

$$
H^{\prime}(1)=-X^{*}=-\sum_{j=0}^{N-1} \frac{\pi_{j}}{1+j}=-\sum_{j=0}^{N-1} \pi_{j} \frac{j r}{(1+j)^{2}}=G^{\prime}(1) \text {. }
$$

So the graph of the linear function $H(\zeta)=1-\zeta X^{* *}$ is tangent at $\zeta=1$ to the graph $\Gamma$ of $y=G(\zeta)$ and since $1>1-\pi_{0}$, and $G^{\prime \prime}(1)>0$, we can say that these two curves intersect twice; at first time for $\zeta=\zeta_{0}<1$ and then for $\zeta=1$, where the two curves are tangent to each other. After the latter point, these two curves do not intersect and thus we have: $\forall \zeta>\zeta_{0}, G(\zeta) \leq H(\zeta)$, with $G(\zeta)=H(\zeta)$ for $\zeta=1$.

If we assume that $\zeta>\zeta_{0}$ or equivalently $X>\zeta_{0} X^{* *}$, the equation $U_{i}=0$ has only one solution, $X=X^{* *}$, and it is a maximum since for $X>\zeta_{0} X^{* *}, K(X)$ has always the same sign given by $G(\zeta)-H(\zeta) \leq 0$ :

$$
\forall X>X_{0} \equiv \zeta_{0} X^{* *}, K(X) \leq 0 \Leftrightarrow \forall X>X_{0} \equiv \zeta_{0} X^{* *}, K(X) \leq K\left(X^{* *}\right) .
$$

\section{Appendix 2 Comparative statics}

In order to perform the comparative statics analysis, let us provide alternative expressions for the first order conditions in (6) and (7). In Appendix 1, it has been shown that condition (6) can be written as:

$$
X=\frac{1}{N p} \sum_{j=1}^{N}\left(\begin{array}{c}
N \\
j
\end{array}\right) p^{j}(1-p)^{N-j}=\frac{1}{N p}\left(1-(1-p)^{N}\right)
$$

thus, according to (21), $\forall p \in[0,1]$ :

$$
\frac{\partial X}{\partial p}=\frac{1}{N p^{2}}\left(N p(1-p)^{N-1}+(1-p)^{N}-1\right)<0 .
$$

Further, it can be shown that the relationship between $X$ and $p$ corresponding to condition (7) can be written as:

$$
\begin{aligned}
X & =\frac{r}{N p}\left[\sum_{j=1}^{N}\left(\begin{array}{c}
N \\
j
\end{array}\right) p^{j}(1-p)^{N-j}\left(\frac{j-1}{j}\right)\right] \\
& =\frac{r}{N p}\left[\sum_{j=1}^{N}\left(\begin{array}{c}
N \\
j
\end{array}\right) p^{j}(1-p)^{N-j}-\sum_{j=1}^{N}\left(\begin{array}{c}
N \\
j
\end{array}\right) p^{j}(1-p)^{N-j} \frac{1}{j}\right] \\
& =\frac{r}{N p}\left(1-(1-p)^{N}\right)-r H(p)
\end{aligned}
$$

where $H(p)$ is given by:

$$
H(p)=\int_{1}^{0}(p x+(1-p))^{N-1} \operatorname{Ln}(x) d x .
$$


To see this, let us expand the polynomial $(p x+(1-p))^{N}$ to obtain:

$$
\begin{aligned}
(p x+(1-p))^{N} & =\sum_{j=0}^{N}\left(\begin{array}{c}
N \\
j
\end{array}\right) p^{j} x^{j}(1-p)^{N-j} \\
& =(1-p)^{N}+x \sum_{j=1}^{N}\left(\begin{array}{c}
N \\
j
\end{array}\right) p^{j} x^{j-1}(1-p)^{N-j}
\end{aligned}
$$

Thus, subtracting $(1-p)^{N}$, dividing by $x$ and integrating in $x$, we have:

$$
\int_{0}^{1} \frac{(p x+(1-p))^{N}-(1-p)^{N}}{x} d x=\int_{0}^{1}\left(\sum_{j=1}^{N}\left(\begin{array}{c}
N \\
j
\end{array}\right) p^{j} x^{j-1}(1-p)^{N-j}\right) d x .
$$

The RHS is:

$$
\left(\sum_{j=1}^{N}\left(\begin{array}{c}
N \\
j
\end{array}\right) p^{j}(1-p)^{N-j}\right)\left(\int_{0}^{1} x^{j-1} d x\right)=\sum_{j=1}^{N}\left(\begin{array}{c}
N \\
j
\end{array}\right) p^{j}(1-p)^{N-j} \frac{1}{j}
$$

while the LHS is:

$$
-N p \int_{0}^{1}(p x+(1-p))^{N-1} \operatorname{Ln}(x) d x=N p H(p) .
$$

Notice also that, since

$$
H^{\prime}(p)=(N-1) \int_{1}^{0}(x-1)(p x+(1-p))^{N-2} \operatorname{Ln}(x) d x
$$

with $x$ taking values on $[0,1]$, it is clear that $H^{\prime}(p)<0$, which is used below.

\section{Comparative statics for $r$}

We will first prove that $\frac{\partial p}{\partial r}<0$ and $\frac{\partial X}{\partial r}>0$. Totally differentiating (6-7) or equivalently (21-22) leads to the system:

$$
\begin{aligned}
\frac{\partial X}{\partial r}= & \frac{\partial p}{\partial r} \frac{1}{N p^{2}}\left(N p(1-p)^{N-1}+(1-p)^{N}-1\right) \\
\frac{\partial X}{\partial r}= & r \frac{\partial p}{\partial r}\left(\frac{1}{N p^{2}}\left(N p(1-p)^{N-1}+(1-p)^{N}-1\right)-H^{\prime}(p)\right) \\
& +\left(\frac{1}{N p}\left(1-(1-p)^{N}\right)-H(p)\right)
\end{aligned}
$$

where $H(p)$ and $H^{\prime}(p)<0$ have been previously defined. Substituting (23) in (24), we obtain:

$$
\frac{\partial p}{\partial r}=\frac{\left(\frac{1}{N p}\left(1-(1-p)^{N}\right)-H(p)\right)}{(1-r)\left(\frac{1}{N p^{2}}\left(N p(1-p)^{N-1}+(1-p)^{N}-1\right)\right)+r H^{\prime}(p)}<0 .
$$


The denominator is negative, while the numerator (which is equal to $X / r$ according to (22)) is positive: as a result $\frac{\partial p}{\partial r}<0$. Then, given (24), it is obvious that:

$$
\operatorname{sign} \frac{\partial X}{\partial r}=-\operatorname{sign} \frac{\partial p}{\partial r}>0 .
$$

Now, we show that $\frac{\partial T}{\partial r}(r, N)=-\frac{\partial D}{\partial r}(r, N)>0$. thus:

Consider that $T(r, N)=(1-p)^{N}$; the impact of an increase in $r$ on the lost treasure is

$$
\frac{\partial T}{\partial r}(r, N)=N(1-p)^{N-1}\left(-\frac{\partial p}{\partial r}\right)>0 .
$$

Thus, by $D(r, N)=1-T(r, N)$, an increase in $r$ has a negative impact on the rent dissipation: $\frac{\partial D}{\partial r}(r, N) \leq 0$.

\section{Comparative statics for $N$}

The analysis of the impact of $N$ is involved, since it requires to solve polynomials of high order, which also depend on $N$. In this case, an alternative informal argument will be sufficient to describe the effects on the equilibrium strategy.

On the one hand, recall that for each participant, the number of his opponents is distributed according to a Binomial law, with a probability to face $j$ opponents equal to $\pi_{j}=\left(\begin{array}{c}N-1 \\ j\end{array}\right) p^{j}(1-p)^{N-1-j}$. It can be shown that:

$$
P(n>k)=\sum_{j=k+1}^{N-1}\left(\begin{array}{c}
N-1 \\
j
\end{array}\right) p^{j}(1-p)^{N-1-j}=\frac{(N-1) !}{k !(N-k-2) !} \int_{0}^{p} t^{k}(1-t)^{N-k-2} d t .
$$

The former relationship implies that $P(n>k)$, which is the cumulative probability that the number of players playing the game is higher than a threshold $k$, is monotonously increasing in $N$. As a result, an increase in $N$ means an increase in the risk borne by each player (in the sense of the first stochastic dominance order) to share the constant prize with a greater number of opponents-the greater the number of players, the smaller the individual share for each player $\left(\frac{1}{1+j}\right)$. To compensate, each player reduces his probability of participation. Thus, the equilibrium value of $p$ decreases in $N$.

On the other hand, $X^{* *}$ cannot increase in $N$, given that $p$ decreases in $N$ and that the expected payoff of a participant is necessarily zero in equilibrium. Numerical simulations performed for $r=2$ give the following results:

\begin{tabular}{cccccccc}
\hline$N$ & 3 & 5 & 8 & 10 & 20 & 50 & 100 \\
\hline$X^{* *}$ & 0.4375 & 0.4040 & 0.3889 & 0.3843 & 0.3757 & 0.3710 & 0.3694 \\
$p^{* *}$ & 0.75 & 0.4753 & 0.3036 & 0.2443 & 0.1235 & 0.0496 & 0.0248 \\
\hline
\end{tabular}

\section{Asymptotic properties for $r$ and $N$}

For strong players we prove the following results with respect to $r$ (for a given $N<\frac{r}{1-r}$ )

$\lim _{r \rightarrow+\infty} X_{0}=\lim _{r \rightarrow+\infty} X^{* *}$ exists and is equal to 1,

$\lim _{r \rightarrow+\infty} p$ exists and is equal to 0 ; 
and with respect to $N$ (for a given $r>\frac{N}{N-1}$ )

$$
\begin{aligned}
& \lim _{N \rightarrow+\infty} X^{* *} \text { exists and is equal to } \frac{1-e^{-a}}{a}, \\
& \lim _{N \rightarrow+\infty} X_{0}<\lim _{N \rightarrow+\infty} X^{* *} \text { exists and is equal to } \zeta_{\infty} \frac{1-e^{-a}}{a}, \\
& \lim _{N \rightarrow+\infty} p \text { exists and is equal to } 0, \\
& \lim _{N \rightarrow+\infty} N p \text { exists and is equal to } a, \\
& \lim _{N \rightarrow+\infty} D \text { exists and is equal to } 1-e^{-a}, \\
& \lim _{N \rightarrow+\infty} T \text { exists and is equal to } e^{-a},
\end{aligned}
$$

where the constant $a$ is the unique, non-negative solution to the equation: $\Psi(a)=\frac{r-1}{r}$ with $\Psi(a)=\int_{0}^{a} \frac{e^{u}-1}{u} d u / \int_{0}^{a} e^{u} d u$.

From (6) ant (7), we know that:

$$
\left\{\begin{array}{l}
X^{* *}=\sum_{j=0}^{N-1}\left(\begin{array}{c}
N-1 \\
j
\end{array}\right) p^{j}(1-p)^{N-1-j} \frac{1}{1+j}<1, \\
X^{* *}=r p \sum_{j=1}^{N-1}\left(\begin{array}{c}
N-1 \\
j
\end{array}\right) p^{j-1}(1-p)^{N-1-j} \frac{j}{(1+j)^{2}} .
\end{array}\right.
$$

So, when $r \rightarrow+\infty$, necessarily $p \rightarrow 0$, because in the second equality both $X^{* *}$ and the sum are bounded. Referring again to the first equality, we can write:

$$
X^{* *}=(1-p)^{N-1}+\sum_{j=1}^{N-1}\left(\begin{array}{c}
N-1 \\
j
\end{array}\right) p^{j}(1-p)^{N-1-j} \frac{1}{1+j} .
$$

Note that $X^{* *} \rightarrow 1$ when $r \rightarrow+\infty$. Now, to describe the minimum effort requirement, let us substitute $X=X_{0}=\zeta X^{* *}$ with $0<\zeta<1$ into (5):

$$
X_{0}=\sum_{j=0}^{N-1}\left(\begin{array}{c}
N-1 \\
j
\end{array}\right) p^{j}(1-p)^{N-1-j} \frac{\zeta_{0}^{r}}{\zeta_{0}^{r}+j}
$$

Terms such as $\frac{\zeta^{r}}{\zeta^{r}+j}$ are bounded by 0 and 1 . Thus $p \rightarrow 0$ implies:

$$
\sum_{j=1}^{N-1}\left(\begin{array}{c}
N-1 \\
j
\end{array}\right) p^{j}(1-p)^{N-1-j} \frac{\zeta^{r}}{\zeta^{r}+j} \rightarrow 0 .
$$

Thus, $X_{0}(r)=\zeta X^{* *} \rightarrow 1$ when $r \rightarrow+\infty$ because $(1-p)^{N-1} \rightarrow 1$. In the same way, from (7) we have:

$$
X^{* *} \geq r p\left((N-1)(1-p)^{N-2} \frac{1}{2^{2}}\right)
$$


Consider $N \rightarrow+\infty$, note that $N p$ is bounded and $p$ (which decreases with $N$ ) approaches 0:

$$
\lim _{N \rightarrow+\infty} p=0 \text {. }
$$

Let us substitute $\theta=\frac{p}{1-p}$ in the equality $B=\frac{r-1}{r} A$ from Proposition 2 of Appendix 1:

$$
\sum_{j=0}^{N-1}\left(\begin{array}{c}
N-1 \\
j
\end{array}\right) \frac{\theta^{j}}{(j+1)^{2}}=\frac{r-1}{r} \sum_{j=0}^{N-1}\left(\begin{array}{c}
N-1 \\
j
\end{array}\right) \theta^{j} .
$$

This relation can be written as:

$$
\int_{0}^{\theta} \frac{(1+x)^{N}-1}{x} d x=\frac{r-1}{r} N \int_{0}^{\theta}(1+x)^{N-1} d x .
$$

Setting $u=N x$ leads to:

$$
\int_{0}^{N \theta} \frac{\left(1+\frac{u}{N}\right)^{N}-1}{u} d u=\frac{r-1}{r} \int_{0}^{N \theta}\left(1+\frac{u}{N}\right)^{N-1} d u .
$$

Finally we have: $F_{N}(N \theta)=\frac{r-1}{r} G_{N}(N \theta)$ with:

$$
F_{N}(t)=\int_{0}^{t} \frac{\left(1+\frac{u}{N}\right)^{N}-1}{u} d u \rightarrow F(t)=\int_{0}^{t} \frac{e^{u}-1}{u} d u \quad \text { when } N \rightarrow+\infty
$$

and

$$
G_{N}(t)=\int_{0}^{t}\left(1+\frac{u}{N}\right)^{N-1} d u \rightarrow G(t)=\int_{0}^{t} e^{u} d u \quad \text { when } N \rightarrow+\infty .
$$

Taking greater values of $N$ in the equality $F_{N}(N \theta)=\frac{r-1}{r} G_{N}(N \theta)$, we can see that $\lim _{N \rightarrow+\infty} N \theta=\lim _{N \rightarrow+\infty} N p$ is the unique, non-negative solution $a$ to the equation $F(a)=$ $G(a)$ :

$$
\int_{0}^{a} \frac{e^{u}-1}{u} d u=\frac{r-1}{r} \int_{0}^{a} e^{u} d u .
$$

Rewriting, $a$ is the unique, non-negative solution to the equation

$$
\Psi(a)=\frac{r-1}{r}, \quad \text { with } \Psi(a)=\int_{0}^{a} \frac{e^{u}-1}{u} d u / \int_{0}^{a} e^{u} d u .
$$

Furthermore, the number $j$ of opponents that a player faces is randomly distributed according to a binomial distribution $B(N-1, p)$. Since $\lim _{N \rightarrow+\infty}(N-1) p=a$, this binomial distribution converges to a Poisson distribution $P(a)$, so that:

$$
\lim _{N \rightarrow+\infty} \pi_{j}=\lim _{N \rightarrow+\infty}\left(\begin{array}{c}
N-1 \\
j
\end{array}\right) p^{j}(1-p)^{N-1-j}=\frac{a^{j} e^{-a}}{j !}
$$

thus, we also have:

$$
\lim _{N \rightarrow+\infty} X^{* *}=\sum_{j=0}^{\infty} \frac{a^{j} e^{-a}}{j !} \frac{1}{1+j}=\frac{e^{-a}}{a}\left[a+\frac{a^{2}}{2 !}+\cdots\right]=\frac{e^{-a}}{a}\left[e^{a}-1\right]=\frac{1-e^{-a}}{a} .
$$


Then when the number of players grows to infinity, we can see that for $r>\frac{N}{N-1}$ the rent dissipation due to the players' efforts is given by:

$$
D_{\infty}=\lim _{N \rightarrow+\infty} N p X^{* *}=1-e^{-a}
$$

and the lost treasure can be written as:

$$
T_{\infty}=e^{-a}
$$

Finally, to describe the minimum level of investment, we use again $X=X_{0}=\zeta X^{* *}$ and (5):

$$
\zeta X^{* *}=\sum_{j=0}^{N-1}\left(\begin{array}{c}
N-1 \\
j
\end{array}\right) p^{j}(1-p)^{N-1-j} \frac{\zeta^{r}}{\zeta^{r}+j} .
$$

When $N \rightarrow+\infty$, we have $\zeta \rightarrow \zeta_{\infty}$, such that:

$$
\begin{aligned}
\zeta_{\infty} \frac{1-e^{-a}}{a} & =\sum_{j=0}^{j=N} \frac{a^{j} e^{-a}}{j !} \frac{\zeta_{\infty}^{r}}{\zeta_{\infty}^{r}+j}, \\
\zeta_{\infty} \frac{e^{a}-1}{a} & =\sum_{j=0}^{j=N} \frac{a^{j}}{j !} \frac{\zeta_{\infty}^{r}}{\zeta_{\infty}^{r}+j} .
\end{aligned}
$$

Defining $g(y)=\sum_{j=0}^{j=N} \frac{a^{j}}{j !} \frac{1}{y+j}$, the latter equation may be written as

$$
\zeta_{\infty}^{r-1} g\left(\zeta_{\infty}^{r}\right)=g(1)
$$

which has only one positive solution, which is less than 1 .

\section{References}

Amegashie, J. A. (1999). The number of rent-seekers and aggregate rent-seeking expenditures: An unpleasant result. Public Choice, 99, 57-62.

Appelbaum, E., \& Katz, E. (1986). Rent seeking and entry. Economics Letters, 20, 207-212.

Barzel, Y. (1997). Economics of property rights (2nd ed.). Cambridge: Cambridge University Press.

Baye, M. R., Kovenock, B., \& de Vries, C. G. (1994). The solution to the Tullock rent-seeking game when $R>2$ : Mixed strategy equilibria and mean-dissipation rates. Public Choice, 81, 363-380.

Baye, M. R., Kovenock, B., \& de Vries, C. G. (1996). The all-pay auction with complete information. Economic Theory, 8, 291-305.

Baye, M. R., Kovenock, B., \& de Vries, C. G. (1999). The incidence of overdissipation in rent-seeking contests. Public Choice, 99, 439-454.

Becker, G. S. (1968). Crime and punishment: An economic approach. Journal of Political Economy, 76, 169-217.

Becker, G. S. (1983). A theory of competition among pressure groups for political influence. Quarterly Journal of Economics, 37, 1-400.

Bhagwati, J. N. (1982). Directly Unproductive, Profit-seeking (DUP) Activities. Journal of Political Economy, 90, 988-1002.

Buchanan, J. M. (1980). Rent seeking and profit seeking. In J. M. Buchanan, R. D. Tollison, \& G. Tullock (Eds.), Towards a theory of the rent-seeking society (pp. 3-15). College Station: Texas A\&M Press.

Buchanan, J. M., Tollison, R. D., \& Tullock, G. (Eds.) (1980). Towards a theory of the rent-seeking society. College Station: Texas A\&M Press.

Clark, D. J. (2000). How unpleasant a result?: A comment on Amegashie. Public Choice, 102, 365-367. 
Coate, S. (2004). Political competition with campaign contribution and informative advertising. Journal of the European Economic Association, 2, 772-804.

Congleton, R. D., \& Tollison, R. D. (Eds.) (1995). The economic analysis of rent seeking. In M. Blaug (Ed.), The international library of critical writings in economics (Vol. 49). Brookfield: Elgar.

Dari-Mattiacci, G., \& Parisi, F. (2005). Rents, dissipation, and lost treasures: Rethinking Tullock's paradox. Public Choice, 124, 411-422.

Demsetz, H. (1976). Economics as a guide to antitrust legislation. Journal of Law and Economics, 19, 371384.

Gradstein, M. (1995). Intensity of competition, entry and entry deterrence in rent-seeking contests. Economics and Politics, 7, 79-91.

Grossman, G., \& Helpman, E. (1996). Electoral competition and special interest politics. Review of Economic Studies, 63, 265-286.

Higgins, R. S., Shughart, W. F., \& Tollison, R. D. (1985). Free entry and efficient rent-seeking. Public Choice, 46, 247-258.

Hillman, A. L., \& Samet, D. (1987). Dissipation of contestable rents by small numbers of contenders. Public Choice, 54, 63-82.

Hirshleifer, J. (1976). Towards a more general theory of regulation: Comment. Journal of Law and Economics, 19, 241-244.

Krueger, A. O. (1974). The political economy of the rent-seeking society. American Economic Review, 64, 291-303.

Lockard, A., \& Tullock, G. (Eds.) (2000). Efficient rent-seeking. Chronicle of an intellectual quagmire. Boston: Kluwer.

Müller, D. C. (2002). Public choice III. Cambridge: Cambridge University Press.

Peltzman, S. (1976). Towards a more general theory of regulation. Journal of Law and Economics, 19, $211-$ 240.

Pérez-Castrillo, D., \& Verdier, T. (1992). A general analysis of rent-seeking games. Public Choice, 73, 335350.

Posner, R. (1975). The social costs of monopoly and regulation. Journal of Political Economy, 83, 807-827.

Rowley, C. K. (1991). Gordon Tullock: Entrepreneur of public choice. Public Choice, 71, 149-169.

Rowley, C. K., Tollison, R. D., \& Tullock, G. (Eds.) (1988). The political economy of rent-seeking. Boston: Kluwer.

Schoonbeek, L., \& Kooreman, P. (1997). Tullock's rent-seeking contest with a minimum expenditure requirement. Public Choice, 93, 477-486.

Stigler, G. (1971). The theory of economic regulation. Bell Journal of Economics and Management Science, 2, 3-21.

Tollison, R. D. (2003). Rent-seeking. In C. K. Rowley, \& F. Schneider (Eds.), Encyclopedia of public choice (Vol. 2, pp. 495-499). Kluwer.

Tullock, G. (1967). The welfare cost of tariffs, monopolies and theft. Western Economic Journal, 5, 224-232.

Tullock, G. (1980). Efficient rent-seeking. In J. M. Buchanan, G. Tollison, \& G. Tullock (Eds.), Toward a theory of the rent-seeking society (pp. 97-112). College Station: Texas A\&M University Press.

Yang, C. L. (1993). Cooperation by credible threats: On the social costs of transfer contest under uncertainty. Journal of Institutional and Theoretical Economics, 149, 559-578. 